\title{
A microwave satellite water vapour column retrieval for polar winter conditions
}

\author{
Christopher Perro $^{1}$, Glen Lesins ${ }^{1}$, Thomas J. Duck ${ }^{1}$, and Maria Cadeddu ${ }^{2}$ \\ ${ }^{1}$ Dalhousie University, Halifax, Nova Scotia, Canada \\ ${ }^{2}$ Argonne National Laboratory, Argonne, IL, USA \\ Correspondence to: Christopher Perro (christopher.perro@dal.ca)
}

Received: 10 June 2015 - Published in Atmos. Meas. Tech. Discuss.: 24 September 2015

Revised: 30 April 2016 - Accepted: 4 May 2016 - Published: 20 May 2016

\begin{abstract}
A new microwave satellite water vapour retrieval for the polar winter atmosphere is presented. The retrieval builds on the work of Miao et al. (2001) and Melsheimer and Heygster (2008), employing auxiliary information for atmospheric conditions and numerical optimization. It was tested using simulated and actual measurements from the Microwave Humidity Sounder (MHS) satellite instruments. Ground truth was provided by the G-band vapour radiometer (GVR) at Barrow, Alaska. For water vapour columns less than $6 \mathrm{~kg} \mathrm{~m}^{-2}$, comparisons between the retrieval and GVR result in a root mean square (RMS) deviation of $0.39 \mathrm{~kg} \mathrm{~m}^{-2}$ and a systematic bias of $0.08 \mathrm{~kg} \mathrm{~m}^{-2}$. These results are compared with RMS deviations and biases at Barrow for the retrieval of Melsheimer and Heygster (2008), the AIRS and MIRS satellite data products, and the ERA-Interim, NCEP, JRA-55, and ASR reanalyses. When applied to MHS measurements, the new retrieval produces a smaller RMS deviation and bias than for the earlier retrieval and satellite data products. The RMS deviations for the new retrieval were comparable to those for the ERA-Interim, JRA-55, and ASR reanalyses; however, the MHS retrievals have much finer horizontal resolution $(15 \mathrm{~km}$ at nadir) and reveal more structure. The new retrieval can be used to obtain pan-Arctic maps of water vapour columns of unprecedented quality. It may also be applied to measurements from the Special Sensor Microwave/Temperature 2 (SSM/T2), Advanced Microwave Sounding Unit B (AMSU-B), Special Sensor Microwave Imager/Sounder (SSMIS), Advanced Technology Microwave Sounder (ATMS), and Chinese MicroWave Humidity Sounder (MWHS) instruments.
\end{abstract}

\section{Introduction}

The polar winter troposphere is very dry, with water vapour columns typically near $3 \mathrm{~kg} \mathrm{~m}^{-2}$ (Serreze et al., 1995). Climate change is expected to increase absolute humidity and alter the polar radiative balance (Stamnes et al., 1998) with consequences for sea ice and global climate. Accurately monitoring polar humidity variations is necessary, but is difficult to do because of the small water vapour concentrations and the few ground-based stations from which observations can be made. Infrared and visible satellite measurements have better spatial coverage but are challenged by scattering and absorption from clouds and the lack of solar radiation during polar winter.

Microwave satellite measurements overcome many of the difficulties. Microwaves have a strong water vapour absorption line at $183 \mathrm{GHz}$ that is useful for dry conditions, with emissions that can be observed during any part of the diurnal cycle. Microwaves are less affected by scattering and absorption from clouds, allowing for water vapour measurements in most weather conditions (Miao et al., 2001). Microwave instruments aboard a series of polar-orbiting satellites since 1991 (F11 to 19, NOAA-15 to 19, MetOP-A and B, FY3A to C, and NPP) already provide a substantial data set for water vapour studies. Planned missions include JPSS-1 and 2, MetOP-C, MetOP-SG, and DMSP-S20.

This paper introduces a modified technique for retrieving water vapour columns from microwave satellite measurements in polar winter conditions that are characterized by low optical depths. The retrieval uses the microwave signal formulation given by Miao (1998, ; hereafter M98). M98's retrieval technique involves several approximations that were 
Table 1. AMSU-B and MHS instrument specifications including frequencies, noise equivalent differential temperature, and nadir polarization orientations (Kleepsies and Watts, 2006). Entries like $183.31 \pm 1 \mathrm{GHz}$ imply that two frequency bands at 182.31 and $184.31 \mathrm{GHz}$ are combined. Vertical and horizontal polarization refers to cross-track and along-track polarization respectively.

\begin{tabular}{cc|cc|cl}
\hline \multicolumn{2}{c|}{ Frequencies $(\mathrm{GHz})$} & \multicolumn{2}{c|}{ Noise (K) } & \multicolumn{2}{c}{ Polarizations } \\
\hline AMSU-B & MHS & AMSU-B & MHS & AMSU-B & MHS \\
\hline 89 & 89 & 0.40 & 0.32 & Vertical & Vertical \\
150 & 157 & 0.80 & 0.53 & Vertical & Vertical \\
$183.31 \pm 1$ & $183.311 \pm 1$ & 0.80 & 0.50 & Vertical & Horizontal \\
$183.31 \pm 3$ & $183.311 \pm 3$ & 0.75 & 0.41 & Vertical & Horizontal \\
$183.31 \pm 7$ & 190.311 & 0.80 & 0.55 & Vertical & Vertical \\
\hline
\end{tabular}

somewhat relaxed in a variation by Melsheimer and Heygster (2008, ; hereafter MH08). Our retrieval (hereafter referred to as PLDC16) employs fewer approximations but requires auxiliary data for the atmospheric conditions. The results are more accurate, but come at the cost of increased computational complexity.

MH08 and PLDC16 are tested against simulated signals in order to determine the impacts of different sources of error. Their performance is also assessed using Microwave Humidity Sounder (MHS) measurements from MetOP-A and NOAA-18 in comparison with surface based G-band vapour radiometer (GVR) measurements at Barrow, Alaska $\left(71.3^{\circ} \mathrm{N}, 156.8^{\circ} \mathrm{W}\right)$. MHS measurements were chosen because they provide the longest period of overlap with the GVR, with continuous water vapour column measurements since 2005 (Cadeddu et al., 2009). The GVR measures brightness temperatures at four double-sideband frequencies near the $183 \mathrm{GHz}$ water vapour absorption line. The water vapour column is estimated to have $5 \%$ error for values between 2 and $7 \mathrm{~kg} \mathrm{~m}^{-2}$ (Cadeddu et al., 2009). Comparisons for water vapour columns less than $8 \mathrm{~kg} \mathrm{~m}^{-2}$ between the GVR and Vaisala radiosondes launched from the ARM Climate Research Facility in Barrow, Alaska have an RMS deviation of $0.23 \mathrm{~kg} \mathrm{~m}^{-2}$. The continuous measurements, relatively low uncertainties, and availability of complementary measurements (most notably a micro pulse lidar) make the GVR an ideal instrument against which to test satellite retrievals.

Similar to the GVR, MHS measures microwave radiances at five frequencies near the $183 \mathrm{GHz}$ water vapour absorption line. MHS is the successor to AMSU-B, the target instrument for MH08's analysis. The specifications for both instruments are summarized in Table 1. The instruments have slightly different frequencies and there is decreased noise for MHS.

The structure of this paper is as follows. Section 2 introduces M98's microwave signal formulation and the three techniques (M98, MH08, and PLDC16) for retrieving water vapour columns. Section 3 describes how different water vapour column regimes are treated. The application of PLDC16 and MH08 to simulated signals is examined in Sect. 4. Section 5 follows by comparing the PLDC16 MHS retrieval with the GVR, other satellite data products (AIRS and MIRS) and atmospheric reanalysis data sets (ERAInterim, NCEP, ASR, and JRA-55). The results are discussed in Sect. 5.3.

\section{Satellite microwave signal formulation and retrieval techniques}

The brightness temperature $T_{i}$ measured at frequency $v_{i}$ by channel $i$ of a satellite-borne microwave instrument is parameterized by (Guissard and Sobieski, 1994)

$T_{i}=m_{p}\left(v_{i}\right) T_{\mathrm{s}}-\left(T_{\mathrm{o}}-T_{\mathrm{c}}\right)\left(1-\varepsilon_{i}\right) e^{-2 \tau_{i} \sec \theta}$,

where $T_{\mathrm{S}}$ is the skin temperature, $T_{\mathrm{o}}$ is the surface air temperature, $T_{\mathrm{c}}$ is the cosmic background temperature, $\varepsilon_{i}$ is the surface emissivity, $\tau_{i} \equiv \tau_{i}(0, \infty)$ is the total optical depth, $\theta$ is the zenith viewing angle of the satellite, and $m_{p}$ is a factor incorporating the vertical structure of the atmosphere. Equation (1) is a combined form of the upwelling and downwelling brightness temperature equations that includes a contribution from cosmic microwave background radiation. $\mathrm{Mi}$ crowave contributions are assumed to be identical in both polarizations, and the surface is assumed to be a perfect specular reflector.

The common idea of M98 and subsequent retrieval schemes is to combine brightness temperatures $T_{1}, T_{2}$, and $T_{3}$ from three channels with $\tau_{1}<\tau_{2}<\tau_{3}$ to obtain

$\frac{\Delta T_{12}-b_{12}}{\Delta T_{23}-b_{23}}=\frac{r_{1}}{r_{2}}\left(\frac{e^{-2 \tau_{1} \sec \theta}-\left(r_{2} / r_{1}\right) e^{-2 \tau_{2} \sec \theta}}{e^{-2 \tau_{2} \sec \theta}-\left(r_{3} / r_{2}\right) e^{-2 \tau_{3} \sec \theta}}\right)$,

where $\Delta T_{12}=T_{1}-T_{2}$ and $\Delta T_{23}=T_{2}-T_{3}$ are brightness temperature differences, and $r_{1}, r_{2}$, and $r_{3}$ are surface reflectances with $r_{i}=1-\varepsilon_{i}$. The factors $b_{12}$ and $b_{23}$ are bias 
coefficients given by

$$
\begin{aligned}
b_{i j}= & \int_{0}^{\infty}\left(e^{-\tau_{j}(z, \infty) \sec \theta}-e^{-\tau_{i}(z, \infty) \sec \theta}\right) \frac{\mathrm{d} T(z)}{\mathrm{d} z} \mathrm{~d} z \\
& +\left(T_{\mathrm{o}}-T_{\mathrm{s}}\right)\left(\varepsilon_{j} e^{-\tau_{j} \sec \theta}-\varepsilon_{i} e^{-\tau_{i} \sec \theta}\right) \\
& +r_{j} e^{-2 \tau_{j} \sec \theta} \int_{0}^{\infty}\left(1-e^{\tau_{j}(z, \infty) \sec \theta}\right) \frac{\mathrm{d} T(z)}{\mathrm{d} z} \mathrm{~d} z \\
& -r_{i} e^{-2 \tau_{i} \sec \theta} \int_{0}^{\infty}\left(1-e^{\tau_{i}(z, \infty) \sec \theta}\right) \frac{\mathrm{d} T(z)}{\mathrm{d} z} \mathrm{~d} z,
\end{aligned}
$$

where $\tau_{i}(z, \infty)$ is the optical depth above altitude $z$.

The three retrieval techniques (M98, MH08, and PLDC16) used to solve for the water vapour column are described next. The retrieval techniques are subject to water vapour column regimes with different frequencies and reflectance choices, and these are discussed in Sect. 3.

\section{$2.1 \quad$ M98}

The M98 retrieval simplifies the formulation of Eqs. (2) and (3). It is assumed that the frequencies for each measurement are similar enough that $r_{1}=r_{2}=r_{3}$, and all but the first term in Eq. (3) is neglected. It is also assumed that water vapour is the only significant absorber in the frequency range of interest and that the total optical depth depends linearly on the water vapour column. This allows a series expansion of Eq. (2) to yield

$W \sec \theta=C_{0}+C_{1} \log \left(\frac{\Delta T_{12}-b_{12}}{\Delta T_{23}-b_{23}}\right)$,

where $W$ is the water vapour column, and $C_{0}$ and $C_{1}$ are coefficients that combine integrated mass absorption coefficients. Notice that the dependence on surface reflectance is eliminated.

M98 assumed constant coefficients $b_{12}, b_{23}, C_{0}$, and $C_{1}$, and determined them using the 1-D radiative transfer model Microwave Model (MWMOD Fuhrhop et al., 1998) with radiosonde profile inputs. A separate calibration is required for each frequency triplet $v_{1}, v_{2}, v_{3}$.

\subsection{MH08}

MH08 proposed a variation of the M98 retrieval for cases with water vapour columns greater than $8 \mathrm{~kg} \mathrm{~m}^{-2}$. Instead of assuming all surface reflectances to be the same, they allow for the possibility that $r_{1}$ differs from $r_{2}=r_{3}$. Following M98, a series expansion of Eq. (2) results in

$W \sec \theta=C_{0}+C_{1} \log \left[\frac{r_{2}}{r_{1}}\left(\frac{\Delta T_{12}-b_{12}}{\Delta T_{23}-b_{23}}+C\right)-C\right]$.

MH08 found $C$ to be constant for the range of water vapour columns under consideration. The coefficients $b_{12}, b_{23}, C_{0}$, and $C_{1}$ were determined using the same approach as in M98 except with a viewing angle dependency. A separate calibration is required for each frequency triplet $v_{1}, v_{2}, v_{3}$. Aircraft measurements of sea ice emissivity were used to establish a constant value for $r_{2} / r_{1}$.

\subsection{PLDC16}

Our approach is to employ Eqs. (2) and (3), but with fewer assumptions. Unlike M98 and MH08, auxiliary information for the atmospheric conditions is required. This information may be obtained from atmospheric reanalyses or other sources.

As a practical matter, the second term in Eq. (3) is ignored. It is proportional to the difference between the skin and surface air temperatures, and comparisons between atmospheric reanalysis products for this factor show considerable disagreement. We also take $r=r_{i}=r_{j}$ in the third and fourth terms of Eq. (3), leaving

$$
\begin{aligned}
b_{i j} \approx & \int_{0}^{\infty}\left(e^{-\tau_{j}(z, \infty) \sec \theta}-e^{-\tau_{i}(z, \infty) \sec \theta}\right) \frac{\mathrm{d} T(z)}{\mathrm{d} z} \mathrm{~d} z \\
& +r\left[e^{-2 \tau_{j} \sec \theta} \int_{0}^{\infty}\left(1-e^{\tau_{j}(z, \infty) \sec \theta}\right) \frac{\mathrm{d} T(z)}{\mathrm{d} z} \mathrm{~d} z\right. \\
& \left.-e^{-2 \tau_{i} \sec \theta} \int_{0}^{\infty}\left(1-e^{\tau_{i}(z, \infty) \sec \theta}\right) \frac{\mathrm{d} T(z)}{\mathrm{d} z} \mathrm{~d} z\right]
\end{aligned}
$$

A constant value for $r$ is assumed, and auxiliary information is used to determine $\mathrm{d} T(z) / \mathrm{d} z$. The sensitivity of our retrieval to these approximations is discussed in Sect. 4.5.

Next, suppose that the true optical depth profile $\tau_{i}(z, \infty)$ is related to a trial optical depth profile $\tau_{i, n}(z, \infty)$ by

$\tau_{i}(z, \infty)=x_{n} \tau_{i, n}$,

where $x_{n}$ is a scaling factor and $n=\{0,1,2,3, \ldots\}$ is the trial number. The trial optical depth profile is given by

$\tau_{i, n}(z, \infty)=\int_{z}^{\infty} k_{i}(p(z), T(z)) w_{n}(z) \mathrm{d} z+\tau_{i}^{\mathrm{o}}(z, \infty)$,

where $p(z)$ and $T(z)$ are pressure and temperature profiles, respectively, $w_{n}$ is the trial water vapour mass density profile, $k_{i}$ is the mass absorption coefficient, and $\tau_{i}^{\mathrm{o}}(z, \infty)$ is the optical depth profile for other constituents (most notably $\mathrm{O}_{2}$ for the $89 \mathrm{GHz}$ channel). We determine $\tau_{i, n}(z, \infty)$ for each trial using the RTTOV 1-D radiative transfer model (Matricardi and Saunders, 1999). Pressure and temperature profiles are taken from the auxiliary information.

The calculation begins with a trial water vapour profile $w_{0}(z)$ taken from the auxiliary estimate. The scaling factor $x_{n}$ is the only unknown variable. It is determined for each 


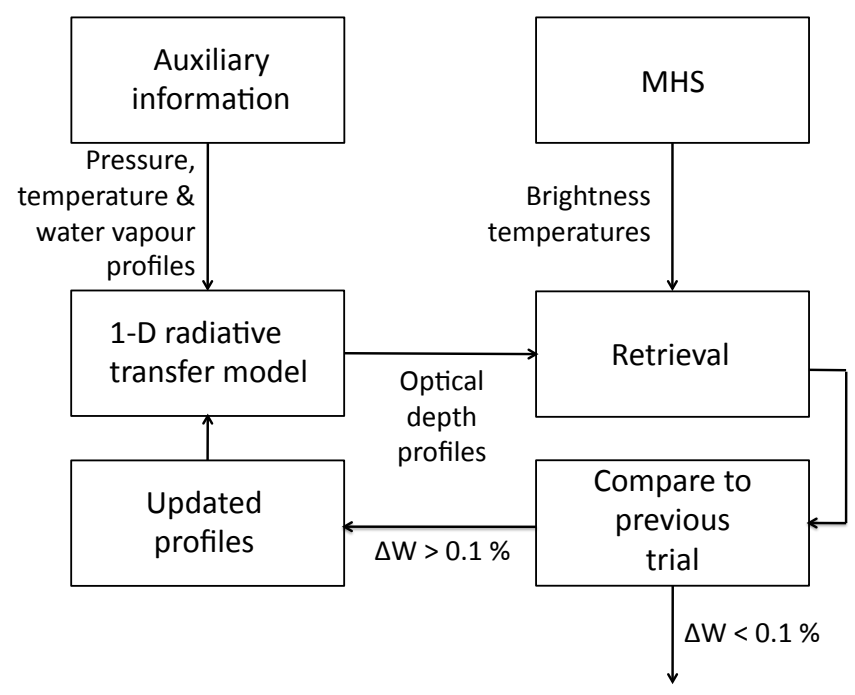

Figure 1. PLDC16 retrieval flow chart. The retrieval starts with auxiliary temperature, pressure, and water vapour profiles as input to a 1-D radiative transfer model. Optical depth profiles are produced for each channel. These are used together with satellite brightness temperatures and Eqs. (2), (6) and (7) to retrieve the scaling factor $x_{n}$ for each trial $n . x_{n}$ is used to scale the trial water vapour profile through Eq. (9) and produce a water vapour column using Eq. (10). If the change $\Delta W$ in the water vapour column between trials is greater than the threshold then the scaled water vapour column is used in the next trial. The process is repeated until convergence is achieved.

trial by solving Eqs. (2), (6) and (7) with a numerical nonlinear optimizer. Trial water vapour profiles for iterations $n>0$ are determined using

$w_{n+1}(z)=x_{n} w_{n}(z)$.

Iterating gradually re-balances the contributions in Eq. (8) between water vapour and other atmospheric constituents.

Having obtained a scaling factor, the water vapour column for iteration $n+1$ is given by

$W_{n+1}=x_{n} \int_{0}^{\infty} w_{n}(z) \mathrm{d} z$.

Note that the final result depends on the shape of the auxiliary water vapour profile but not on its column amount.

Unlike M98 or MH08 there is no need to perform a separate frequency calibration. We stop iterating when the change in the water vapour column is less than $0.1 \%$ between iterations. The number of iterations varies for each measurement, and a maximum of 20 iterations is applied. Figure 1 summarizes the PLDC16 retrieval process.

Although it is not inherently required by the formulation above, for the remainder of this paper we shall assume that the influence of liquid clouds and ice crystals on the retrieval is negligible. The mass absorption coefficient for liquid water in particular is almost constant across the frequencies of
Table 2. MHS frequencies for the low, mid, and extended regimes for the retrievals of water vapour column with typical water vapour column $(W)$ ranges. The frequencies $v_{1}, v_{2}$ and $\nu_{3}$ in each regime are ordered so that $\tau_{1}<\tau_{2}<\tau_{3}$.

\begin{tabular}{lc|c|cr}
\hline Regime & \multicolumn{3}{c}{ MHS frequencies $(\mathrm{GHz})$} & \multirow{W}{W}{$\begin{array}{c}W \text { range } \\
\left(\mathrm{kg} \mathrm{m}^{-2}\right)\end{array}$} \\
\cline { 2 - 4 } & $v_{1}$ & $v_{2}$ & $v_{3}$ & $0-2.5$ \\
Low & 190.311 & $183.311 \pm 3$ & $183.311 \pm 1$ & $1.5-9$ \\
Mid & 157 & 190.311 & $183.311 \pm 3$ & $8-15$ \\
Extended & 89 & 157 & 190.311 & \\
\hline
\end{tabular}

interest (Miao et al., 2001). The impact of this assumption is explored in Sect. 5.3.

\section{Regime selection}

Three sets of frequencies are used for MHS retrievals, giving rise to the "low", "mid", and "extended" regimes, as summarized in Table 2. These correspond to measurements at highly, moderately, and weakly absorbed frequencies. M98 applies to only the low and mid regimes while MH08 and PLDC16 apply to all three. The retrievals use different criteria for choosing between regimes.

Brightness temperatures typically increase with increasing water vapour column, but decrease for larger columns as the weighting function peaks at higher (and therefore colder) altitudes. M98 therefore switches from the low to mid regime when $\Delta T_{12}>0$ or $\Delta T_{23}>0$. MH08 switches to a higher regime if $\Delta T_{12}-b_{12}>0$ or $\Delta T_{23}-b_{23}>0$.

A difficulty with the above approach is that brightness temperatures are strongly affected by temperature profile structure, and in particular by surface temperature inversions that are ubiquitous during polar winter (e.g. Lesins et al., 2010, 2012). This causes regime selection artifacts, as will be seen in Sect. 4.1.

We take a different approach. The slant water vapour column is determined from auxiliary information, with the slant given by the instrument's viewing angle. The low regime is used for slant water vapour columns between 0 and $2.5 \mathrm{~kg} \mathrm{~m}^{-2}$, the mid regime is used from 1.5 to $9 \mathrm{~kg} \mathrm{~m}^{-2}$, and the extended regime is used above $8 \mathrm{~kg} \mathrm{~m}^{-2}$. The boundaries of the regimes were chosen by comparing multiple GVR and PLDC16 water vapour columns. When a regime becomes too moist for its strongest absorbing frequency, the retrieval shows a decrease in sensitivity with increasing water vapour. By comparing the RMS deviation and bias for adjacent regimes the optimal regime for a particular range of water vapour column was chosen. Weighted averages are used where regimes overlap in order to smooth the transition. Measurements near the lower boundary of a regime sometimes do not have a solution, and in this case the nearest regime in terms of the slant water vapour column is used. 
MH08 retrievals in the low and mid regimes assume $r_{1}=$ $r_{2}=r_{3}$, and as such it is equivalent to M98 in those regimes. For the extended regime, the reflectance $r_{1}$ is taken to be different from $r_{2}=r_{3}$ because of the separation in frequencies. MH08 found a ratio $r_{2} / r_{1}=1.22$ from the Surface Emissivities in Polar Regions Polar Experiment (SEPOR/POLEX) aircraft campaign measurements. It is important to note that this value is fixed in their retrieval because it is used in the determination of the constants $C_{0}$ and $C_{1}$ in Eq. (5).

For the PLDC16 retrieval, we assume $r_{1}=r_{2}=r_{3}$ in the low regime, $r_{1}$ different from $r_{2}=r_{3}$ in the mid regime, and all three reflectances different in the extended regime. Because there are no pre-determined coefficients in our retrieval, we are able to set the reflectance ratios as required. Different assumptions were made for the simulations and measurement retrievals, as will be explained.

\section{Retrieval performance with simulated measurements}

To test the retrieval techniques, we used the RTTOV 1-D radiative transfer model to simulate brightness temperature measurements, employing operational radiosonde profiles from Barrow, Alaska as inputs. A total of 1490 profiles between December and March for 2008 to 2014 were used. The maximum water vapour column allowed was $15 \mathrm{~kg} \mathrm{~m}^{-2}$.

All simulations assumed nadir satellite measurements, and the surface air and skin temperatures were taken to be equal. The surface reflectance was set to 0.2 for all frequencies in both the simulations and retrievals. Simulations at different viewing angles show insignificant differences in the retrieval of the water vapour column.

RTTOV was used to provide cloud-free brightness temperatures for both the MHS and AMSU-B instruments. We used AMSU-B simulations for MH08's retrieval given that their retrieval coefficients are calibrated for that instrument. MHS simulations were used for our retrieval.

The retrieval techniques were tested against three different cases, with results given in Sects. 4.1-4.3:

1. simulated signals with no detector noise and perfect auxiliary information;

2. simulated signals with detector noise and perfect auxiliary information;

3. simulated signals with detector noise and climatological auxiliary information.

In each case we compare the retrieved water vapour columns against the input columns. The simulations are also used in Sect. 4.5 to evaluate the impacts of our assumptions, and in Sect. 4.6 to evaluate the possibility of applying the MH08 retrieval to MHS measurements. All three cases assume perfect knowledge of the surface reflectance.
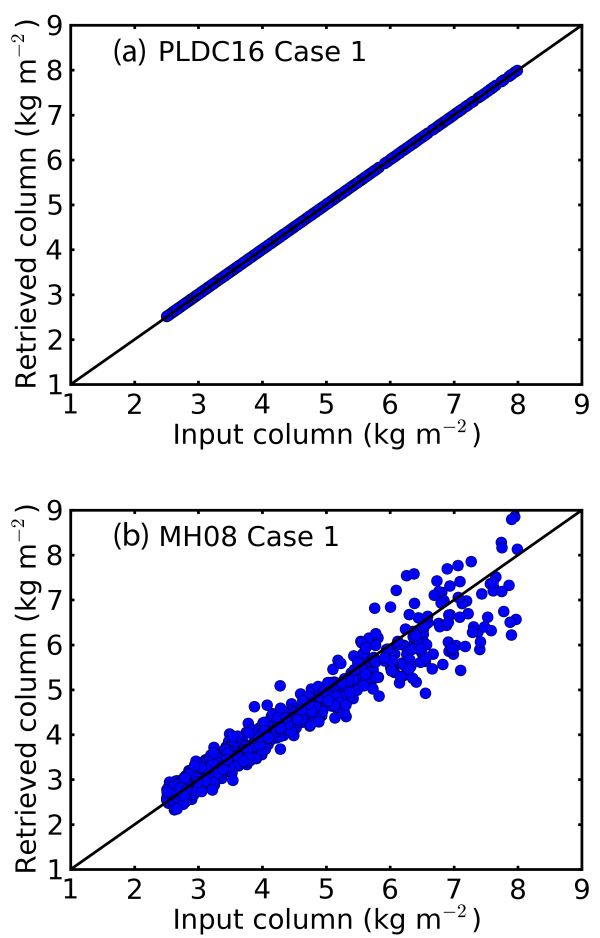

Figure 2. Comparisons of mid regime retrievals (excluding overlap) from simulated signals against the input water vapour columns for (a) PLDC16 and (b) MH08. The simulated signals are noiseless and perfect auxiliary information is provided. The black line represents a perfect retrieval.

\subsection{Case 1}

The intrinsic accuracy of each retrieval is tested by using noiseless simulated signals and perfect auxiliary information. Figure 2 compares mid regime retrievals $\left(2.5\right.$ to $8 \mathrm{~kg} \mathrm{~m}^{-2}$, excluding overlap) to simulated water vapour columns. RMS deviation and bias values are given in Table 3. The PLDC16 retrieval has negligible RMS deviations and biases. This is expected given the ideal conditions for the test, with non-zero values arising from the small disagreements between RTTOV and our radiative transfer parameterization. The greater scatter and bias values for MH08 are due to the inherent error in that retrieval's constant coefficients. The reduction of standard error by PLDC16 over MH08 is due entirely to the calculation of bias coefficients. Iterations have an insignificant effect on the retrieval.

Figure 3 shows results for the three combined regimes. The MH08 retrieval shows significant bias at the boundary between the low and mid regimes $\left(2.5-3 \mathrm{~kg} \mathrm{~m}^{-2}\right)$. It can also be seen that the mid regime extends up to approximately $10 \mathrm{~kg} \mathrm{~m}^{-2}$, which is where the extended regime should be used.

Table 3 summarizes the low, mid, and extended regime results for both retrievals. Similar to the mid regime, the standard deviation for the PLDC16 low and extended regimes is 
Table 3. Root mean square deviation (RMSD) and bias $\left(\mathrm{kg} \mathrm{m}^{-2}\right)$ for PLDC16 and MH08 retrievals from simulated signals for the low, mid and extended regimes (excluding overlap). Results from three cases are provided. Case 1 uses noiseless simulated brightness temperatures with perfect auxiliary information. Case 2 uses simulated brightness temperatures with Gaussian noise and perfect auxiliary information. Case 3 uses simulated brightness temperatures with Gaussian noise and a climatological auxiliary profile. Case 3 does not include a column for combined measurements because regime selection requires better auxiliary information.

\begin{tabular}{|c|c|c|c|c|c|c|c|c|}
\hline & \multicolumn{2}{|c|}{ Low } & \multicolumn{2}{|c|}{ Mid } & \multicolumn{2}{|c|}{ Extended } & \multicolumn{2}{|c|}{ Combined } \\
\hline & RMSD & Bias & RMSD & Bias & RMSD & Bias & RMSD & Bias \\
\hline \multicolumn{9}{|l|}{ Case 1} \\
\hline PLDC16 & 0.00 & 0.00 & 0.00 & 0.01 & 0.00 & 0.07 & 0.01 & 0.01 \\
\hline MH08 & 0.08 & 0.10 & 0.35 & -0.10 & 0.57 & -0.67 & 0.67 & 0.13 \\
\hline \multicolumn{9}{|l|}{ Case 2} \\
\hline PLDC16 & 0.10 & 0.00 & 0.23 & 0.03 & 0.34 & 0.11 & 0.19 & 0.02 \\
\hline MH08 & 0.13 & 0.10 & 0.41 & -0.07 & 0.68 & -0.63 & 0.64 & 0.12 \\
\hline \multicolumn{9}{|l|}{ Case 3} \\
\hline PLDC16 & 0.13 & 0.05 & 0.44 & -0.13 & 0.59 & -1.24 & $\mathrm{n} / \mathrm{a}$ & $\mathrm{n} / \mathrm{a}$ \\
\hline MH08 & 0.13 & 0.10 & 0.41 & -0.07 & 0.68 & -0.63 & $\mathrm{n} / \mathrm{a}$ & $\mathrm{n} / \mathrm{a}$ \\
\hline
\end{tabular}

significantly less than for MH08. There is a positive bias in the extended regime of the PLDC16 retrieval, and this is due again to the small disagreement between RTTOV and our parameterized radiative transfer.

\subsection{Case 2}

Gaussian-distributed noise with a standard deviation of $0.5 \mathrm{~K}$ was added to the simulated brightness temperatures for this second case. The value was chosen to be consistent with the noise equivalent differential temperature for the MHS instruments (see Table 1). Perfect auxiliary information was provided to the retrievals.

Figure 4 compares the PLDC16 and MH08 mid regime retrievals to the input water vapour column. The RMS deviations are increased compared to case 1 , but more so for PLDC16 (see Table 3). Nevertheless, the RMS deviation for MH08 is $78 \%$ greater than for PLDC16. The reduction of standard error by PLDC16 over MH08 is due primarily to the calculation of bias coefficients. In the extended regime, however, iterations account for $24 \%$ of the overall correction.

Table 3 summarizes the results for the low, mid, and extended regimes. In each case the PLDC16 retrieval has a smaller standard deviation and bias. PLDC16's RMS deviation is significantly lower for combined regimes, although this is partly due to the improved regime selection of PLDC16. The results indicate that the PLDC16 retrieval is more accurate if there is perfect auxiliary information.

\subsection{Case 3}

In the third case climatological auxiliary information is used, which represents severely degraded knowledge of the at-
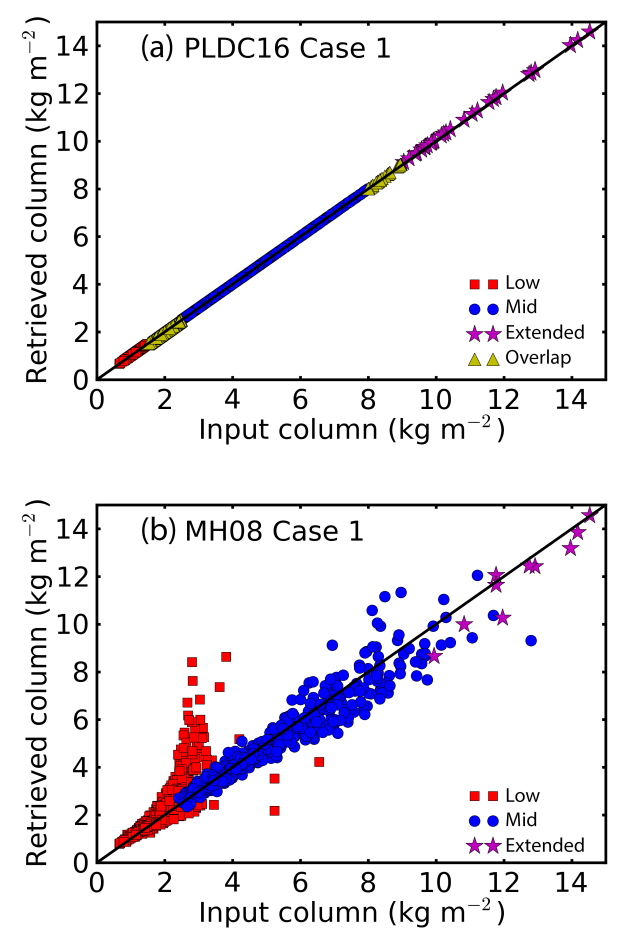

Figure 3. Comparisons of combined regime retrievals from simulated signals against the input water vapour columns for (a) PLDC16 and (b) MH08. The simulated signals are noiseless and perfect auxiliary information is provided. The black line represents a perfect retrieval. 

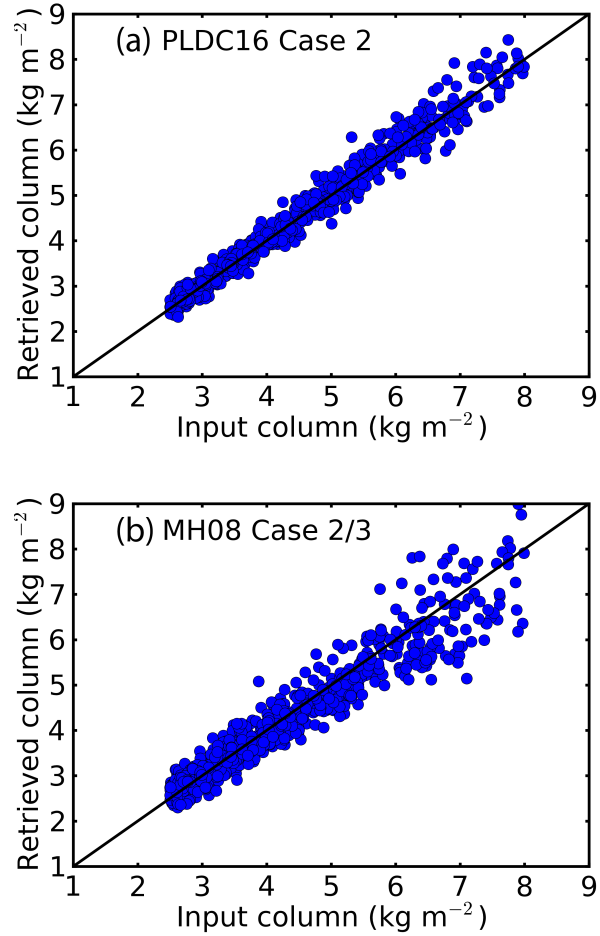

Figure 4. Comparisons of mid regime retrievals (excluding overlap) from simulated signals against the input water vapour columns for (a) PLDC16 and (b) MH08. The simulated brightness temperatures include Gaussian noise with a $0.5 \mathrm{~K}$ standard deviation, and perfect auxiliary information is provided. The black line represents a perfect retrieval.

mospheric conditions. The climatological water vapour and temperature profiles were obtained by averaging the profiles from all 1490 measurements considered in this study. The noise and MH08 retrievals are the same as for Case 2.

Figure 5 compares the PLDC16 retrieval to the input water vapour column for the mid regime. The RMS deviation is $0.21 \mathrm{~kg} \mathrm{~m}^{-2}$ larger than for Case 2, and $0.03 \mathrm{~kg} \mathrm{~m}^{-2}$ larger than for MH08. The low regime results (not shown) are nearly the same. For the extended regime (not shown), PLDC16 performs slightly better in terms of RMS deviation, but has significantly larger bias. The results show that when the auxiliary information is severely degraded, the PLDC16 retrieval can be expected to perform comparably to MH08 for the low and mid regimes.

\subsection{Discussion}

Three test cases were given to theoretically evaluate the PLDC16 and MH08 retrievals. Case 1 tests their intrinsic accuracy for noiseless brightness temperatures and perfect auxiliary information. Both retrievals performed as expected, with the PLDC16 retrieval faithfully reproducing the model water vapour data. Case 2 included randomized noise as found in the MHS instruments. Given perfect auxiliary in-
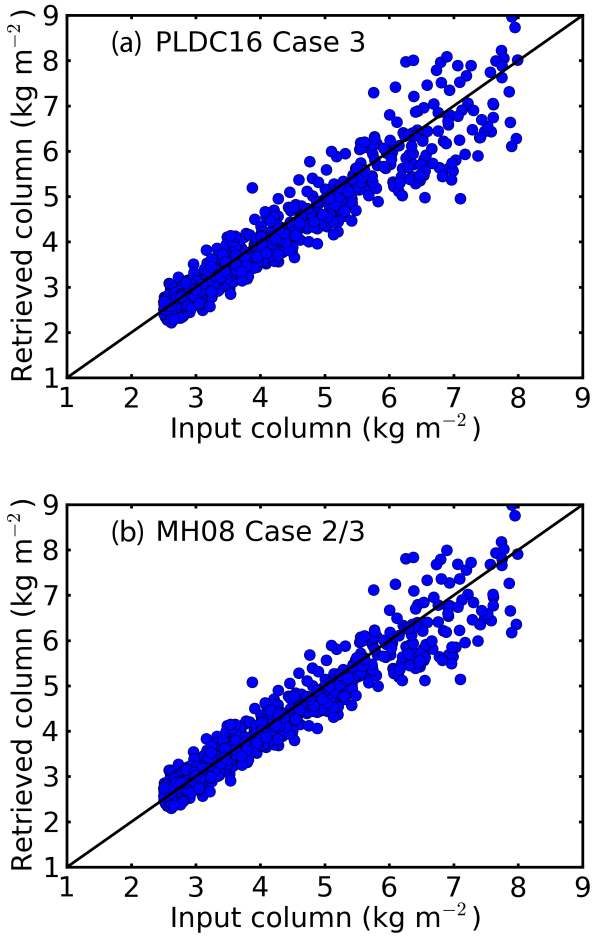

Figure 5. Comparison of the mid regime retrieval (excluding overlap) from simulated signals against the input water vapour columns for PLDC16. The simulated brightness temperatures include Gaussian noise with a $0.5 \mathrm{~K}$ standard deviation, and climatological auxiliary information is used. The black line represents a perfect retrieval.

formation, the PLDC16 retrieval more accurately reproduced the model water vapour. Case 3 employed climatological auxiliary information, which represents a worst-case scenario for PLDC16. The test yielded comparable errors for the two retrievals for the low and mid regimes.

We expect that reanalysis data will always be available to provide auxiliary information. As such, the most realistic retrieval comparison is given by Case 2. Notwithstanding, there are uncertainties in reanalyses (Serreze et al., 2012), spatiotemporal variations in water vapour distribution (Bühler et al., 2012; Tobin et al., 2006), and systematic uncertainties which are difficult to treat quantitatively in simulations. Results from testing in real-world conditions are given in Sect. 5.

\subsection{Assessment of PLDC16 assumptions}

Simulations may also be used to assess the impact of two approximations made in the development of the PLDC16 retrieval.

i. The second term of Eq. (3), which contains the difference between the surface air and skin temperatures, was ignored. 
Table 4. Root mean square deviation (RMSD) and bias $\left(\mathrm{kg} \mathrm{m}^{-2}\right)$ for MH08 retrievals from simulated signals for the low, mid and extended regimes (excluding overlap). The AMSU-B results are the same as in Case 1 from Table 3.

\begin{tabular}{lrr|rr|rr}
\hline & \multicolumn{2}{c|}{ Low } & \multicolumn{2}{c|}{ Mid } & \multicolumn{2}{c}{ Extended } \\
\cline { 2 - 7 } Retrieval & RMSD & Bias & RMSD & Bias & RMSD & Bias \\
\hline AMSU-B & 0.08 & 0.10 & 0.35 & -0.10 & 0.57 & -0.67 \\
MHS & 0.08 & 0.06 & 0.37 & 0.11 & 0.64 & 1.96 \\
\hline
\end{tabular}

ii. A constant value for $r=r_{i}=r_{j}$ must be assumed in Eq. (6) and may be in error.

Case 1 simulations were performed so that we could completely isolate the effects of each item.

To evaluate the impact of (i), we ran simulations with $T_{\mathrm{o}}-T_{\mathrm{S}}= \pm 5 \mathrm{~K}$ and $\pm 2 \mathrm{~K}$. Note that although atmospheric reanalyses often disagree on $T_{\mathrm{o}}-T_{\mathrm{S}}$, values up to $2 \mathrm{~K}$ are typical for multi-year Arctic sea ice (Melsheimer and Heygster, 2008). As such, the $\pm 5 \mathrm{~K}$ test represents an extreme case.

We found that inclusion of $T_{\mathrm{o}}-T_{\mathrm{S}}$ in the simulations caused a bias in the retrieved water vapour columns. The bias was positive for $T_{\mathrm{o}}-T_{\mathrm{S}}>0$ and negative for $T_{\mathrm{O}}-T_{\mathrm{S}}<0$. The bias varied for each regime in the retrieval. The low regime bias for $T_{\mathrm{o}}-T_{\mathrm{s}}= \pm 5 \mathrm{~K}$ ranged from 3 to $5 \%$ with increasing water vapour column. Similarly the mid regime bias ranged from 3 to $7 \%$ and the extended regime bias ranged from 3 to $4 \%$. For the more typical case with $T_{\mathrm{O}}-T_{\mathrm{S}}=2 \mathrm{~K}$, we found a bias in all regimes of less than $3 \%$.

To assess the impact of (ii), we performed separate simulations using surface reflectance values of 0.05 and 0.35 , which represent extremes in the Arctic (Selbach, 2003), for all channels. Assuming $r=0.12$ in Eq. (6) provides the best retrieval. We found that a maximum random error of less than $3 \%$ in the water column was introduced. The error is largest for the low-humidity end of each regime.

\subsection{Evaluation of MHO8 as applied to MHS measurements}

The MH08 retrieval was designed for application to AMSUB measurements. Section 5, however, applies the MH08 retrieval to MHS measurements instead. The error due to the application of MH08 to MHS can be assessed using the simulations from Case 1.

Table 4 shows the results when MH08 is applied to simulated MHS and AMSU-B brightness temperatures for each regime. In the low regime both the RMS deviation and bias are small. The mid regime's bias effectively changes sign and the RMS deviation increases by $6 \%$. For the extended regime the RMS deviation increases by $12 \%$, whereas the absolute bias increases by $193 \%$. We conclude that the MH08 retrieval can be reasonably applied to MHS measurements for the low and mid regimes.
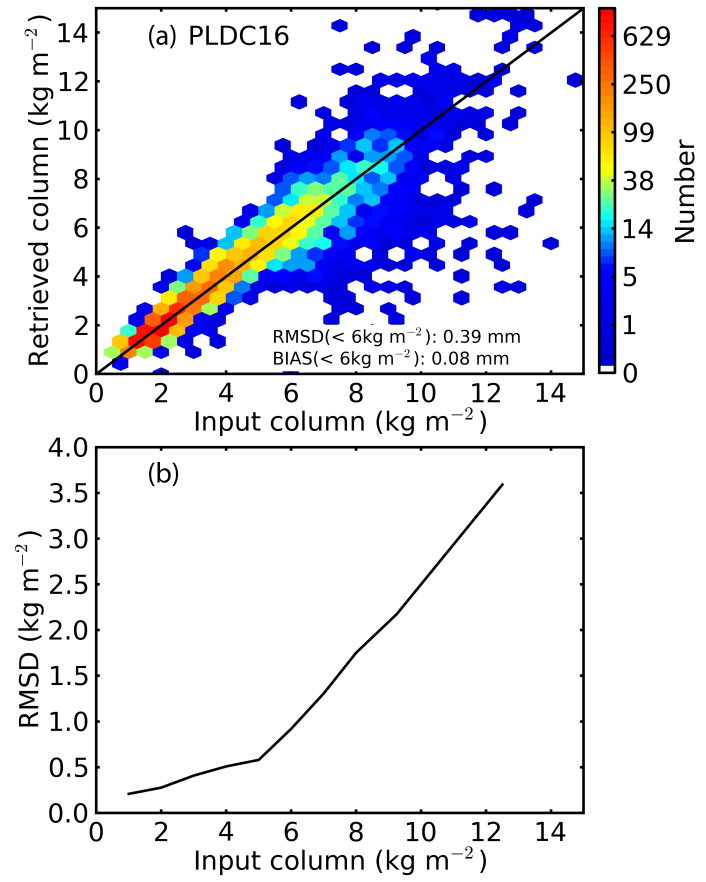

Figure 6. (a) PLDC16 retrieval of water vapour column from MHS brightness temperatures compared to GVR retrievals at Barrow, Alaska. (b) The corresponding root mean square deviations (RMSDs).

The simulations do not account for the difference in polarization measured by the two instruments. This has an unknown effect on the retrieved columns.

\section{Measurements}

This section examines PLDC16 water vapour columns retrieved from MHS overpasses of Barrow, Alaska. The retrievals are compared with simultaneous GVR measurements and a variety of other data sets. Swath data are used to illustrate the spatial distribution of retrieved water vapour columns.

\subsection{Assessment of water vapour column using GVR}

A total of 11333 MHS measurements from MetOP-A and NOAA-18 within $50 \mathrm{~km}$ of Barrow, Alaska were obtained for the same time period as in Sect. 4. We retrieved water vapour columns from these data using PLDC16 with the ERA-Interim reanalysis providing auxiliary information. ERA-Interim data have an $80 \mathrm{~km}$ resolution in latitude and are provided four times per day.

For the reflectance ratio in the mid regime we chose $r_{1} / r_{2}=1.12$ from SEPOR/POLEX data which is representative of ice and open water (Selbach, 2003). For the extended regime, we chose $r_{1} / r_{2}=1.19$ for a mixture of coastal ice and snow-covered land using MACSI aircraft campaign data 
Table 5. Water vapour column root mean square deviations (RMSDs) for various data sets against GVR measurements for columns less than $6 \mathrm{~kg} \mathrm{~m}^{-2}$. Values in brackets give the deviations and biases as a fraction of the mean column amount.

\begin{tabular}{llrrrr}
\hline Data set/retrieval & $\begin{array}{r}\text { Nadir resolution } \\
(\mathrm{km})\end{array}$ & Samples & $\begin{array}{r}\text { RMSD } \\
\left(\mathrm{kg} \mathrm{m}^{-2}\right)\end{array}$ & Bias $\left(\mathrm{kg} \mathrm{m}^{-2}\right)$ \\
\hline Reanalyses & & & & \\
\hline NCEP & 280 & 2693 & $0.79(29.9 \%)$ & $-0.04(-1.6 \%)$ \\
JRA-55 & 140 & 2694 & $0.39(14.8 \%)$ & $-0.49(-18.7 \%)$ \\
ASR ( 2012$)$ & 30 & 4047 & $0.40(15.6 \%)$ & $-0.18(-6.9 \%)$ \\
ERA-Interim & & & & & \\
\hline Satellite & & & & & \\
\hline AIRS & combined & 45 & 10774 & $1.03(38.9 \%)$ & $-0.34(-12.8 \%)$ \\
& infrared & & & $1.10(41.6 \%)$ & $-0.22(-8.3 \%)$ \\
MIRS (MHS DJFM 2013/4) & microwave & & & $1.05(39.6 \%)$ & $0.11(4.1 \%)$ \\
MH08 (AMSU-B $\leq 2009)$ & & 15 & 1002 & $0.69(22.0 \%)$ & $-0.18(-5.7 \%)$ \\
MH08 (MHS) & 15 & 4277 & $0.95(39.2 \%)$ & $0.20(8.1 \%)$ \\
PLDC16 (MHS) & 15 & 9739 & $0.71(27.2 \%)$ & $0.23(8.6 \%)$ \\
\hline
\end{tabular}

(Hewison and English, 1999). The second ratio was chosen to be $r_{2} / r_{3}=1.12$ as these are the same frequencies as $r_{1} / r_{2}$ from the mid regime.

Figure 6 shows the results of the PLDC16 retrieval compared to coincident GVR measurements in terms of water vapour column. The GVR obtains four measurements per minute (Pazmany, 2007), and these are averaged over $3 \mathrm{~min}$ to reduce noise.

For the full data set the RMS deviation is $0.72 \mathrm{~kg} \mathrm{~m}^{-2}$ and the bias is $0.02 \mathrm{~kg} \mathrm{~m}^{-2}$. Note, however, that the error is larger at water vapour columns greater than $6 \mathrm{~kg} \mathrm{~m}^{-2}$. The RMS deviation and bias for GVR-measured columns less than $6 \mathrm{~kg} \mathrm{~m}^{-2}$ are reduced to 0.39 and $0.08 \mathrm{~kg} \mathrm{~m}^{-2}$, respectively. During the dry Arctic winter the water vapour column is typically less than $6 \mathrm{~kg} \mathrm{~m}^{-2}$ (Przybylak, 2015).

Table 5 provides a statistical comparison of various water vapour data sets with the GVR, all for GVR-measured columns less than $6 \mathrm{~kg} \mathrm{~m}^{-2}$. Reanalysis data sets include the European Centre for Medium-Range Weather Forecasts (ECMWF) ERA-Interim product (Dee et al., 2011), the National Centers for Environmental Prediction (NCEP; Kalnay et al., 1996) product, the Arctic System Reanalysis (ASR; Bromwich et al., 2010), and the Japanese 55 year Reanalysis (JRA-55; Kobayashi et al., 2015). Satellite products included were the Atmospheric Infrared Sounder (AIRS) Divakarla et al., 2006), Microwave Integrated Retrieval System (MIRS) (Boukabara et al., 2010), MH08 retrieval, and PLDC16 retrieval. AIRS satellite data included three different products: infrared measurements, microwave measurements (using AMSU-A), and combined (infrared and microwave) measurements. MIRS is a data product that uses a one dimensional variational inversion scheme (1D-VAR) in conjunction with satellite measurements from MHS and AMSU sensors to determine atmospheric quantities such as water vapour column. MH08 was applied to both the MHS and AMSUB instruments and PLDC16 was applied to MHS.

Table 5 shows that the RMS deviation and bias for PLDC16 MHS retrievals is smaller than for the other satellite data products. The MH08 retrievals from MHS measurements also have smaller RMS deviations than most of the other satellite data products. The comparison between the PLDC16 and MH08 results is consistent with our conclusions from Sect. 4.

The PLDC16 retrieval has similar RMS deviations to the ASR, ERA-Interim, and JRA-55 reanalyses; NCEP, on the other hand, has RMS deviations that are twice as large. The JRA-55 bias is significantly larger than every other reanalysis and satellite product in this comparison. The biases are negative for each of the reanalyses ranging from -0.04 to $-0.49 \mathrm{~kg} \mathrm{~m}^{-2}$. The excellent performance of the reanalyses is not surprising given that they incorporate data from radiosonde launches at Barrow. It is unclear how the measurements and analyses compare away from the radiosonde anchor points, and this is the subject of ongoing study.

\subsection{Spatial distributions of water vapour column}

As an example of how PLDC16 can be applied to swath data, Fig. 7a shows the retrieval for the NOAA-18 MHS measurement from 31 January 2008. The area chosen is centred over the Chukchi Sea north of Alaska. The ERA-Interim reanalysis was used to provide auxiliary information, and the reflectance ratios from Sect. 5.1 were used for simplicity. A detailed analysis of the Arctic-wide, reflectance-dependent PLDC16 retrieval is left for future work.

The plot shows individual footprints which vary in size due to the MHS's viewing angle. For comparison, Fig. 7b 
(a) PLDC16

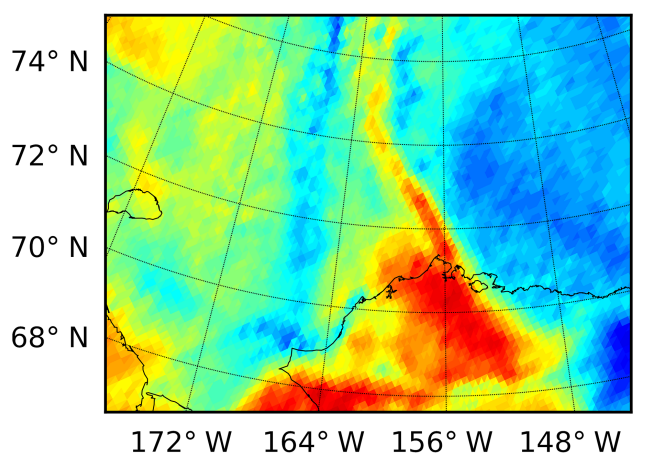

(b) ASR

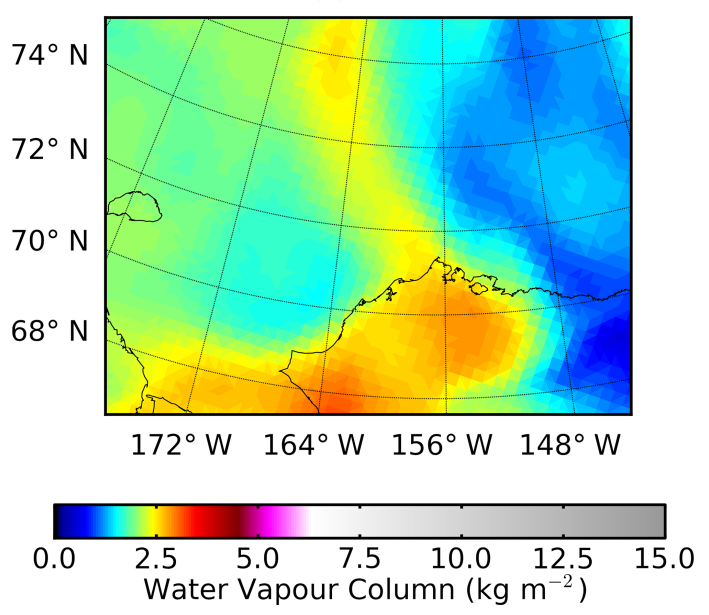

Figure 7. The spatial distribution of water vapour column centred over the Chukchi Sea north of Barrow, Alaska: (a) the PLDC16 retrieval from NOAA-18 MHS brightness temperature measurements on 31 January 2008 at 23:09 UTC; and (b) the Arctic System Reanalysis (ASR) product for 1 February 2008 at 00:00 UTC.

shows the equivalent ASR water vapour column for the same period. The ASR resolution is $30 \mathrm{~km}$ in latitude. The comparison reveals PLDC16 applied to MHS data has the finer intrinsic resolution. The ASR reanalysis tends to smooth out fine details in the water vapour column.

\subsection{Uncertainties}

The PLDC16 errors in the measurements of Sect. 5 were greater than were obtained for the simulations in Sect. 4. This is not unexpected. Sources of error that exist in measurements that are not simulated include:

i. differences in the scene viewed by GVR and MHS;

ii. uncertainties in the reflectance ratio terms in the mid and extended regimes;

iii. uncertainties in the auxiliary temperature profile (Serreze et al., 2012);
Table 6. Water vapour column root mean square deviations (RMSDs) for PLDC16 retrievals using different auxiliary data sets against GVR measurements for columns less than $6 \mathrm{~kg} \mathrm{~m}^{-2}$.

\begin{tabular}{lrr}
\hline Auxiliary & $\begin{array}{r}\text { RMSD } \\
\left(<6 \mathrm{~kg} \mathrm{~m}^{-2}\right)\end{array}$ & $\begin{array}{r}\text { Bias } \\
\left(<6 \mathrm{~kg} \mathrm{~m}^{-2}\right)\end{array}$ \\
\hline AIRS Combined & 0.41 & -0.02 \\
NCEP & 0.52 & 0.20 \\
JRA-55 & 0.44 & 0.16 \\
ASR $(\leq 2012)$ & 0.46 & 0.08 \\
ERA-Interim & 0.39 & 0.08 \\
ERA-Interim (monthly mean) & 0.46 & 0.09 \\
\hline
\end{tabular}

iv. optically thick ice crystal and liquid water clouds;

v. removal of the second term in Eq. (3);

vi. changes with time in MHS noise;

vii. polarization in the MHS measurements for different frequencies;

viii. uncertainties in the GVR measurements;

ix. the assumption of a purely specular reflecting surface.

The error in (i) arises from the GVR being a stationary zenith-pointing instrument, while the satellite-borne MHS has varying downward-pointing viewing angles. The criteria for an overpass match in Sect. 5 allows the centre of the MHS footprint to be up to $50 \mathrm{~km}$ from Barrow, Alaska. Any geophysical variation in the water vapour field can be expected to result in differences between the two measurements. The viewing geometry error can potentially be larger than the random error from either instrument. Bühler et al. (2012) estimated the error to vary from 0.66 to $1.05 \mathrm{~kg} \mathrm{~m}^{-2}$ for the AMSU-B's largest footprints. The impact of elevation differences at Barrow for the various data products were tested using the Case 3 simulations. The terrain around Barrow ranges from heights of 7 to $20 \mathrm{~m}$ with small amounts of vegetation. Our calculations indicate differences in water vapour columns of less than $1 \%$ owing to elevation variations.

The error in (ii) depends on the regime and frequencies selected. SEPOR/POLEX data show a high correlation for the 157 and $183 \mathrm{GHz}$ surface emissivity measurements over different sea ice types. The high correlation corresponds to a small range of 0.96 to 1.13 for the reflectance ratio $\left(r_{1} / r_{2}\right.$ for mid, $r_{2} / r_{3}$ for extended) over different types of sea ice and water surfaces. The 89 and $157 \mathrm{GHz}$ surface emissivity measurements have very little correlation and produce a large range of 0.56 to 1.26 for the reflectance ratio $\left(r_{1} / r_{2}\right.$ for extended regime). The range of $r_{1} / r_{2}$ for the mid regime term translates to a variation in the water vapour column of $25 \%$. Similarly, in the extended regime, the range of $r_{2} / r_{3}$ results 
in a variation of $2 \%$, and the large range of $r_{1} / r_{2}$ yields a variation of $143 \%$.

For (iii), Table 6 provides RMS deviations from GVR measurements for the PLDC16 retrieval using different reanalyses for the auxiliary information. Only GVR water vapour columns of less than $6 \mathrm{~kg} \mathrm{~m}^{-2}$ were considered. The results from Table 6 show the RMS deviation varies only slightly depending on the data set used to provide auxiliary information. The ERA-Interim auxiliary information provides the smallest RMS deviation while the NCEP auxiliary information gives the largest. Even the ERA-Interim monthly mean profile provides a good retrieval, indicating that the monthly mean provides a reasonable representation of the profile shape. Note, however, that the daily ERA-Interim reanalysis was still used for the regime selection.

For (iv), MHS measurements at Barrow were separated into cases with liquid water clouds, ice clouds, and clear skies by using micro pulse lidar (MPL) backscatter and depolarization data. The PLDC16 retrieval was applied to each set of measurements and then compared to radiosonde measurements that came within $1 \mathrm{~h}$ of the MHS measurements. Radiosonde measurements were used because the GVR and MHS might observe similar effects given that they are both microwave instruments. The liquid water and ice cloud cases had increases in the RMS deviation of 0.06 and $0.05 \mathrm{~kg} \mathrm{~m}^{-2}$, respectively, when compared to the clear sky cases. The bias did not change significantly between the three cases. This indicates that clouds do not present a large source of error in the retrieval.

For (v), the removal of the second term in the retrieval equation typically translates to a change of $3 \%$ in water vapour column (as discussed in Sect. 4.5). The error of the GVR measurements in (viii) is $\pm 5 \%$. Other sources of error are difficult to quantify.

\section{Conclusions}

A new retrieval based on the microwave formulation developed by Miao et al. (2001) was introduced. Simulations show that the new technique reduces errors compared to earlier approaches when good auxiliary information for the atmospheric conditions is used. In a comparison with ground-truth measurements, the new PLDC16 retrieval provides more accurate water vapour columns than other satellite measurements.

Maps of water vapour can be created that reveal fine structure that reanalyses do not discern. Pan-Arctic water vapour charts can be created twice per day using the combination of overpasses from NOAA-18 and MetOP-A alone. Temporal resolution may be further improved by including additional instruments. Given historical satellite data sets and planned launches, microwave water vapour measurements may provide new insights into changing Arctic conditions. Complications arising from varying microwave surface emissivity were not treated in this paper, which only examines the retrieval at a single location. A follow-on paper that applies the retrieval in a pan-Arctic context will explore this important topic.

Acknowledgements. The Microwave Surface and Precipitation Products System (MSPPS) provided the MHS brightness temperatures from NOAA and MetOP series satellites operated by the National Oceanic and Atmospheric Administration (NOAA) and the European Organisation for the Exploitation of Meteorological Satellites (EUMETSAT), respectively. The Satellite Application Facility for Numerical Weather Prediction (NWP SAF) provided the RTTOV radiative transfer model. The Atmospheric Radiation Measurement (ARM) program supported the GVR. The Goddard Earth Sciences Data and Information Services Center (GES DISC) provided the AIRS data set. ECMWF provided ERA-Interim data set. The Japan Meteorological Agency (JMA) provided the JRA-55 data set. NOAA/OAR/ESRL PSD provided the NCEP reanalysis data. The Polar Meteorology Group from Ohio State University provided the ASR data set.

Edited by: T. von Clarmann

\section{References}

Boukabara, S., Garrett, K., and Chen, W.: Global Coverage of Total Precipitable Water Using a Microwave Variational Algorithm, IEEE T. Geosci. Remote, 48, 3608-3621, 2010.

Bromwich, D., Kuo, Y., Serreze, M., Walsh, J., Bai, L., Barlage, M. Hines, K., and Slater, A.: Arctic system reanalysis: call for community involvement, EOS T. Am. Geophys. Un., 91, 13-14, 2010.

Bühler, S. A., Östman, S., Melsheimer, C., Holl, G., Eliasson, S., John, V. O., Blumenstock, T., Hase, F., Elgered, G., Raffalski, U., Nasuno, T., Satoh, M., Milz, M., and Mendrok, J.: A multiinstrument comparison of integrated water vapour measurements at a high latitude site, Atmos. Chem. Phys., 12, 10925-10943, doi:10.5194/acp-12-10925-2012, 2012.

Cadeddu, M., Turner, D., and Liljegren, J.: A neural network for real-time retrievals of PWV and LWP from Arctic millimeter wave ground based observations, IEEE T. Geosci. Remote, 9, 1887-1900, 2009.

Dee, D., Uppala, S., Simmons, A., Berrisford, P., Poli, P., Kobayashi, S., Andrae, U., Balmaseda, M., Balsamo, G., Bauer, P., Bechtold, P., Belijaars, A., van de Berg, L., Bidlot, J., Bormann, N., Delsol, C., Dragani, R., Fuentes, M., Geer, A., Haimberger, L., Healy, S., Hersbach, H., Hólm, E., Isaksen, L., Kållberg, P., Köhler, M., Matricardi, M., McNally, A., Monge-Sanz, B., Morcrette, J., Park, B., Peubey, C., de Rosnay, P., Tavolato, C., Thépaut, J., and Vitart. F.: The ERA interim reanalysis: configuration and performance of the data assimilation system, Q. J. Roy. Meteor. Soc., 137, 553-597, 2011.

Divakarla, M., Barnet, C., Goldberg, M., McMillin, L., Maddy, E., Wolf, W., Zhou, L., and Liu, X.: Validation of atmospheric infrared sounder temperature and water vapor retrievals with matched radiosonde measurements and forecasts, J. Geophys. Res., 111, D09S15, doi:10.1029/2005JD006116, 2006. 
Fuhrhop, R., Grenfell, T., Heygster, G., Johnsen, K., Schliissel, P., Schrader, M., and Simmer, C.: A combined radiative transfer model for sea ice, open water, and atmosphere, Radio Sci., 33, 303-316, 1998.

Guissard, A. and Sobieski, P.: A simplified radiative transfer equation for application in ocean microwave remote sensing, Radio Sci., 29, 881-894, 1994.

Hewison, T. and English, S.: Airborne retrievals of snow and ice surface emissivity at millimeter wavelengths, IEEE T. Geosci. Remote, 37, 1871-1879, 1999.

Kalnay, E., Kanamitsu, M., Kistler, R., Collins, W., Deaven, D., Gandin, L., Iredell, M., Saha, S., White, G., Woollen, J., Zhu, Y., Leetmaa, A., Reynolds, R., Chelliah, M., Ebisuzaki, W., Higgins, W., Janowiak, J., Mo, K. C., Ropelewski, C., Wang, J., Jenne, R., and Joseph, D.: The NCEP NCAR 40 year reanlysis project, B. Am. Meteorol. Soc., 77, 437-470, 1996.

Kleepsies, T. and Watts, P.: Comparison of simulated radiances, Jacobians and linear error analysis for the microwave humidity sounder and the advanced microwave sounding unit B, Q. J. Roy. Meteor. Soc., 132, 3001-3010, 2006.

Kobayashi, S., Ota, Y., Harada, Y., Moriya, M., Onoda, H., Onogi, K., Kamahori, H., Kobayashi, C., Endo, H., Miyaoka, K., and Takahashi, K.: The JRA 55 reanalysis: general specifications and basic characteristics, IEEE T. Geosci. Remote, 93, 5-48, 2015.

Lesins, G., Duck, T., and Drummond, J.: Climate trends at Eureka in the Canadian high Arctic, Atmos. Ocean, 48, 59-80, 2010.

Lesins, G., Duck, T., and Drummond, J.: Surface energy balance framework for Arctic amplification of climate change, J. Climate, 25, 8277-8288, 2012.

Matricardi, M. and Saunders, R.: Fast radiative transfer model for simulation of infrared atmospheric sounding interferometer radiances, Appl. Optics, 38, 5679-5691, 1999.

Melsheimer, C. and Heygster, G.: Improved retrieval of total water vapor over polar regions from AMSU-B microwave radiometer data, IEEE T. Geosci. Remote, 46, 2307-2322, 2008.
Miao, J.: Retrieval of Atmospheric Water Vapor Content in Polar Regions Using Spaceborne Microwave Radiometry, Alfred Wegener Inst. Polar Marine Res., Bremerhaven, Germany, 1998.

Miao, J., Kunzi, K., Heygster, G., Lachlan-Cope, T., and Turner, $\mathrm{J} .:$ Atmospheric water vapor over Antarctica derived from special sensor microwave/temperature 2 data, J. Geophys. Res., 106, 10187-10203, 2001.

Pazmany, A.: A compact $183 \mathrm{GHz}$ radiometer for water vapor and liquid sensing, IEEE T. Geosci. Remote, 45, 2202-2207, 2007.

Przybylak, R.: The Climate of the Arctic second edition, Kluwer Academic Publishers, Norwell, MA, USA, 2015.

Selbach, N.: Determination of Total Water Vapor and Surface Emissivity of Sea Ice at $89 \mathrm{GHz}, 157 \mathrm{GHz}$ and $183 \mathrm{GHz}$ in the Arctic Winter, PhD thesis, University of Bremen, Bremen, Germany, 2003.

Serreze, M., Barry, R., and Walsh, J.: Atmospheric water vapor characteristics at $70 \mathrm{~N}$, J. Climate, 8, 719-731, 1995.

Serreze, M., Barrett, A., and Stroeve, J.: Recent changes in tropospheric water vapor over the Arctic as assessed from radiosondes and atmospheric reanalyses, J. Geophys. Res.,117, D10104, doi:10.1029/2011JD017421, 2012.

Stamnes, K., Ellingson, R., Curry, J., Walsh, J., and Zak, B.: Review of science issues, deployment strategy, and status for the ARM north slope of Alaska-Adjacent Arctic Ocean Climate Research Site, J. Climate, 12, 46-63, 1998.

Tobin, D., Revercomb, R., Knuteson, R., Lesht, B., Strow, L., Hannon, S., Feltz, W., Moy, L., Fetzer, E., and Cress, T.: Atmospheric Radiation Measurement site atmospheric state best estimates for Atmospheric Infrared Sounder temperature and water vapor retrieval validation, J. Geophys. Res., 111, D09S14, doi:10.1029/2005JD006103, 2006. 